Vol.16, No.60, July 2021, 789-801

\title{
GEOSTATISTICAL MODELLING FOR SULFUR ELEMENT IN GHORABI IRON ORE MINE AREA, BAHARIYA OASIS, EGYPT
}

\author{
A. F. Ismael
}

Al-Azhar University, Faculty of Engineering, Mining and Petroleum Department, Cairo, Egypt.

*Corresponding Author E-mail: Ashraffahmy72@yahoo.com

Received: 25 May 2021 Accepted: 20 June 2021

\begin{abstract}
Sulfur is a concern in Ghorabi iron ore and it is an unwanted component when the ore is charged into a blast furnace. The goal of this paper aims to track the sulfur content in Ghorabi iron ore by using geostatistical modelling. Geologically, the ore is split into four distinct zones. The experimental variograms were created to highlight the spatial variability of sulfur element within the deposit. The experimental variograms were fitted with Gaussian, linear and exponential variogram models. Finally, the appropriate fitted models were utilized to create a distribution maps for the four separated zones using the ordinary kriging and indicator kriging in $0.7 \%$ cut-offs.
\end{abstract}

KEY WORDS: Sulfur Element, Geostatistics GS+, Variogram, Ordinary and Indicator Kriging, Iron Ore Ghorabi Mine Area.

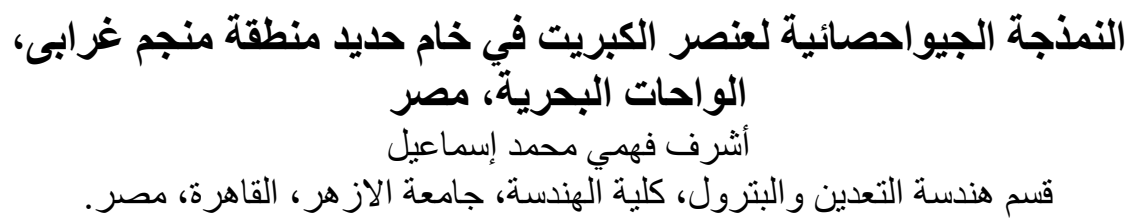

يمثل الكبريت مشكلة في خام حديد منطقة غر ابي ويعتبر مكونًا غير مرغوب فيه عند شحن الخام للفرن العالي. تهدف هذه الورقة إلى رصد تباين الكبريت الموجود في خام حديد منطقة غر ابي باستخدام النمذجة الجيو إحصائية. تم تقسيم الخام جيولوجياً إلى أربع مناطق منفصلة. لإظهار التباين المكاني لعنصر الكبريت ، تم إنشاء المتغيرات التجريبية داخل الرواسب. تم تركيب نماذج التباين (جاوسيان - الخطية ـ الأسية) للمتغيرات التجريبية. أخيرًا ، تم استخدام 
النماذج المناسبة لإنشاء خر ائط توزيع لعنصر الكبريت باستخدام الكريجنج العادي و الكريجنج المؤشر لحد قطع معين للمناطق الأربعة المختلفة.

الكلمات الرئيسية: عنصر الكبريت ، الجيو إحصاء GS + أنكال التباين ، كريجنج عادي ومؤشر ، منطقة منجم خام حديد غر ابي.

\section{INTRODUCTION}

The quality of the raw materials used in the blast furnace had a significant impact on the performance, particularly the iron ore and its undesired elements associated with the raw material. Mineralogical characterization aids in the identification of the distinct mineral phases and associated gangue constituents, which have a significant impact on the process's bulk chemistry and hot metal quality [1].

$\mathrm{Fe}_{2} \mathrm{O}_{3}, \mathrm{FeO}, \mathrm{SiO}_{2}, \mathrm{Al}_{2} \mathrm{O}_{3}$ are the major components of iron burden. Some of the major harmful elements in iron ore material for iron manufacturing and subsequent steel manufacturing which will be present in quality ore are mentioned below along with their permissible limits.

- Sulfur (environment hazard): should be kept below $0.01 \%$

- $\mathrm{Na}_{2} \mathrm{O}+\mathrm{K}_{2} \mathrm{O}$ : should not more than $0.8 \%$

- Zinc: $0.02 \%$ is the maximum allowable limit.

- Phosphorous: not more than $0.04 \%$

- $\mathrm{Mn}_{2} \mathrm{O}$ maximum allowable $3.2 \%$

- $\mathrm{SiO}_{2}$ should not exceed $8 \%$

The variogram is defined as the difference in values between samples separated by a certain distance as a measure of their spatial correlation [1]. The most important and initial step in any geostatistical analysis is constructing of an experimental variogram. It can be calculated from a set of randomly spaced data by selecting pairs of data that are oriented in the desired direction, calculating the distance between the samples, adding the squared differences of the grades and dividing by the number of pairs [2]. Kriging offers the most accurate approximation of a regionalized variable's mean value. It calculates the grade's Best Linear Unbiased Estimator (BLUE). Each sample is given a sample weight during kriging. The best estimate is then obtained by linearly combining the weighted samples. The approach reduces the predicted error between the estimated grade and the true grade. The sample weights are set in such a way that the estimate's variance is kept to a minimal [3]. In this paper the sulfur element in Ghorabi iron ore is modelled using geostatistical methodology is used for methodology. 


\section{GEOLOGY OF THE STUDIED AREA}

The Bahariya Oasis Depression is one of Egypt's seven major depressions in the western desert. It is located $160 \mathrm{Km}$ west of the Nile valley and $320 \mathrm{Km} \mathrm{SW}$ of Cairo160 Km west of the Nile valley and $320 \mathrm{Km} \mathrm{SW}$ of Cairo, between latitudes $27^{\circ} 48^{\prime}$ and $28^{\circ} 30^{\prime} \mathrm{N}$., and between longitudes $28^{\circ} 30^{\prime}$ and $29^{\circ} 10^{\prime} \mathrm{E}$. The depression is oval-shaped, extending during a north east-south west trend. It has a maximum length of $100 \mathrm{Km}$ along its NE$\mathrm{SW}$ axis, and a maximum width of $45 \mathrm{Km}$. The depression is surrounded by plateaus which rise 250 - $300 \mathrm{~m}$ above MSL. It is closed from all directions by steep scarps.

These scarps are dissected by wadies which end internally at the depression floor. Gentle slopes except for the relatively steep slopes of the isolated hills and hillocks characterize the floor of the depression. The iron ore occurrences i.e., Ghorabi, and Nasser and Structural setting of the NE plateau of El-Bahariya Depression are illustrated in Fig. 1. Ghorabi area structurally divided into four zones $[4,5]$.

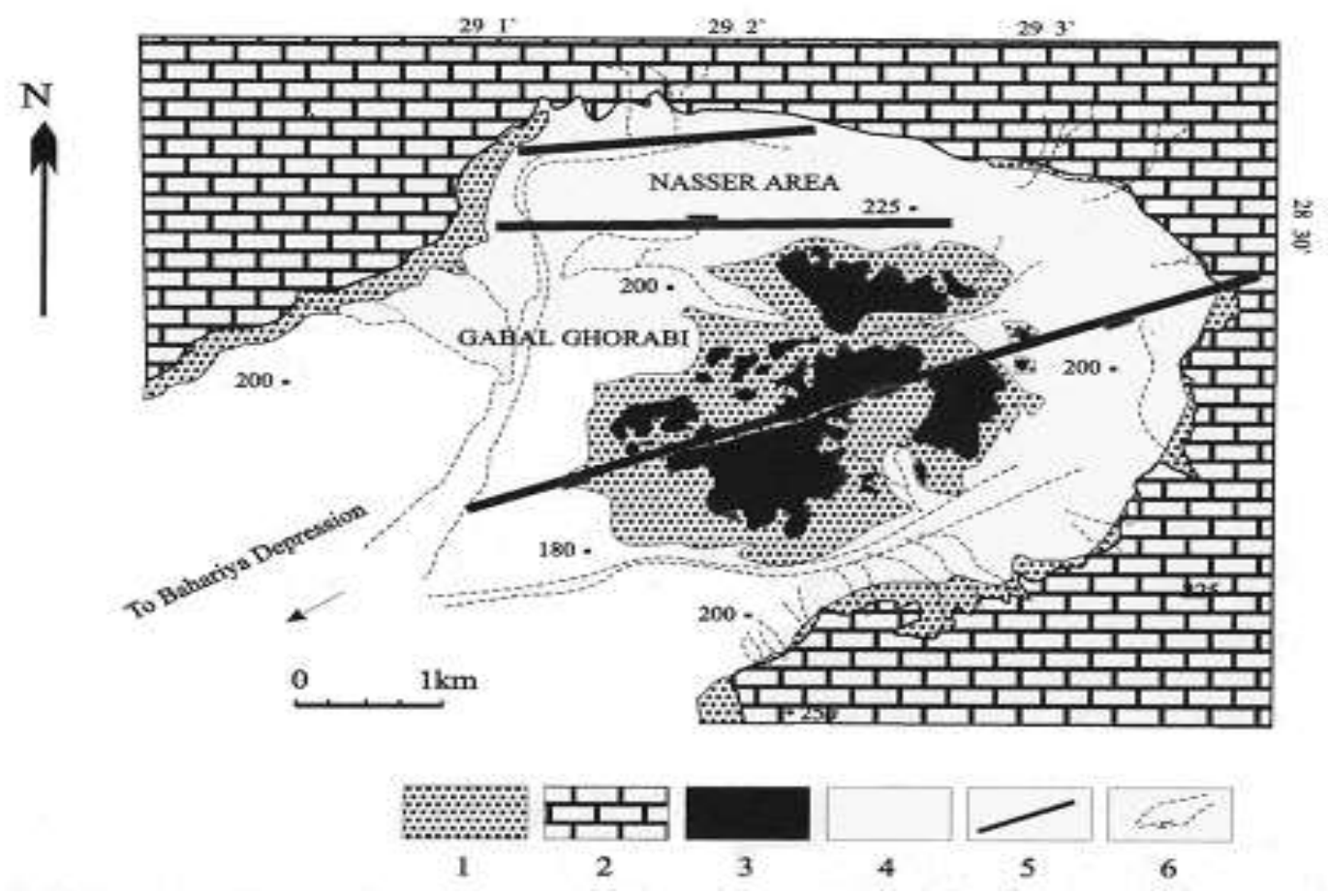

Fig. 1: Simplified geological map of Ghorabi - Nasser area [6] 1= The Cenomanian Bahariya Fm. Clastic rocks; 2= The middle Eocene Naqb Fm. karstified limestone; 3= Iron ore deposits; 4= Quaternary sediments; $5=$ Faults; $6=$ Drainage lines. 


\section{METHODOLOGY}

The geostatistical application's primary goal is to know the behavior of the natural occurrences. Because of this benefit, this technology has been employed in variety fields, including mining, hydraulic, petroleum, and meteorology, etc. This technique can be carried out in two steps. The geostatistical technique begins with the creation of a mathematical function related with the regional dependence [7]. It's known as the semivariogram function (SV).

The determination of a highly correlated SV function is the most critical stage in the geostatistical technique. As a result, a valid interpretation of the distribution is available. It is possible to comprehend the regional behavior of the natural phenomena at each point in the studied area by using kriging technique.

\subsection{Variogram}

The variogram is a geostatistical tool for visualizing, modeling, and exploiting a regionalized variable's spatial autocorrelation [8]. A variogram, as the name implies, is a variance measure. The computer program can then calculate estimates that reflect the spatial extent and orientation of autocorrelation in the variable to be mapped using a suitably fitted model [9].

The variogram's goal is to identify the distance across which values in the data set are interdependent, i.e., it's used to determine the range of influence, and hence the weights to be used in interpolation between observations. It also allows for the explicit computation of variance [10].

Calculating the difference $\mathrm{z}(\mathrm{x})-\mathrm{z}(\mathrm{x}+\mathrm{h})$ between site $\mathrm{x}$ and a site $\mathrm{h}$ far, say $\mathrm{x}+\mathrm{h}$, is a simple means of determining how a variable $z$ changes in value between site $x$ and a site $h$ unit away, say $x+h$. If the two points represent a continuous surface and $h$ is a tiny distance, the difference should be minimal as well. If $h$ is large in comparison to the spatial degree of change within the variable, the difference is likely to increase in value. Putting this intuitive idea into a formula (1), which is as follows:

$\gamma(\mathrm{h})=\frac{1}{2 \mathrm{n}} \sum[\mathrm{z}(\mathrm{x})-\mathrm{z}(\mathrm{x}+\mathrm{h})]^{2}$

\subsubsection{Standard variogram models}

The majority of geostatistical estimation and simulation techniques require an analytical variogram model, which they will replicate with statistical variation [11]. The variogram models presented in Fig. 2 are some the most regularly utilized [12]: 

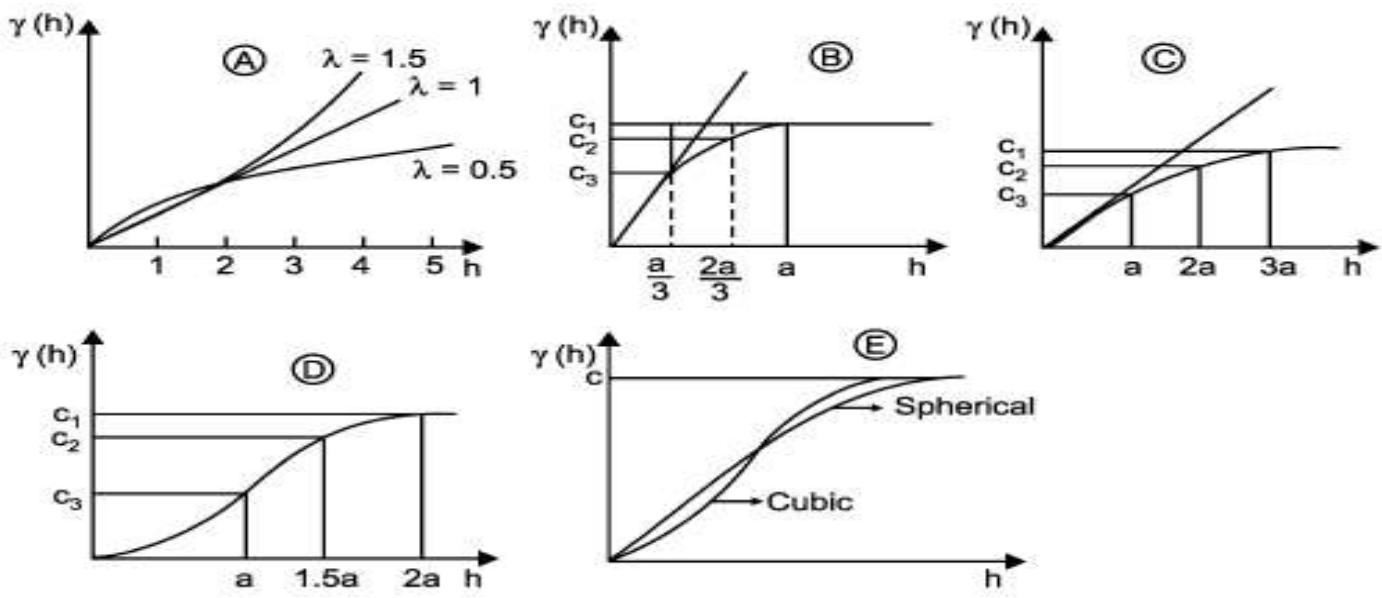

Fig. 2: Some the most regularly utilized variogram models: A- Power Functions, B- Spherical Model, C- Exponential Model, D- Gaussian Model and E- Cubic Model.

\subsection{Kriging}

Kriging is a broad term for a prediction approach. It necessitates a mathematical model to represent spatial covariance, which is commonly described as a variogram, which has become the primary tool of geostatistics in its parameterized form. Successful kriging and variogram estimation require adequate sample without bias as well as appropriate spatial configurations and supports. These differ from design-based estimate in that they place a greater focus on random sampling [13].

Kriging is a statistically sound spatial prediction technique. according to the formula (2), kriging uses the same weighted linear combination estimator.

$$
\hat{z}=\sum_{i=1}^{n} w_{i} z_{i}
$$

Where the sample value at point ${ }_{i}$ is $\mathrm{Z}_{\mathrm{i}}$, the weight is $\mathrm{W}_{\mathrm{i}}$, and the number of samples is $\mathrm{n}$. The previous estimators are unbiased if the sum of the weights is 1 , as will be clarified later. The goal of kriging to minimize the error variance, which is its unique property [14].

\subsubsection{Ordinary kriging $(\mathrm{OK})$}

Kriging is normally done with a variogram rather than covariogram in practice since it has better statistical features (unbiased \& consistent). From equation (3):

$$
\gamma(h)=\mathrm{C}(0)-\mathrm{C}(\mathrm{h}), \quad \mathrm{C}(\mathrm{h})=\mathrm{C}(0)-\gamma(h)
$$


The formula (4) is obtained by substituting this covariogram into the unconstrained (MSE) mean squared error:

$$
\begin{aligned}
M S E & =\sum_{i} \sum_{j} w_{i} w_{j}\left(\sigma^{2}-\gamma_{i j}\right)+\sigma^{2}-2 \sum w_{i}\left(\sigma^{2}-\gamma_{i 0}\right)+2 \lambda\left(\sum w_{i}-1\right) \\
& =-\sum_{i} \sum_{j} w_{i} w_{j} \gamma_{i j}+2 \sum w_{i} \gamma_{i 0}+2 \lambda\left(\sum w_{i}-1\right) .
\end{aligned}
$$

The weights are frequently solved by setting the equations of the first derivatives w.r.t. wi's to zero, similar to the covariogram. [15].

\subsubsection{Indicator kriging (IK)}

Kriging of indicator variables, which represent membership in a set of categories, is especially useful for preserving the connectedness of high and low permeability regions when used with naturally categorical variables like facies or continuous variables that have been thresholded into categories (e.g., quartiles, deciles). When kriging is applied directly to perm, extreme values are almost always washed out.

Indicator Kriging creates binary data ( 0 or 1 values), using thresholds, and then utilizes ordinary kriging to construct geographical predictions using the indicator data. The likelihood of exceeding the stated threshold is calculated using indicator kriging predictions [16].

Indicator Kriging is based on the following model:

$I(s)=\mu+\varepsilon(s)$

Where $\varepsilon(\mathrm{s})$ is a binary variable and $\mu$ is an unknown constant.

It's possible to create binary data by using threshold for continuous data, or it's also possible that the observed data is 0 or 1 .

\section{EXPERIMENTAL WORK}

In blast furnace shaft, the sulfur in iron ore and coke was removed by the ascending gas and the sulfur removed there at $1000{ }^{\circ} \mathrm{C}$ escaped more into gas than into lime. It is too harmful if exceeds than a special limit and it is necessary to remove from the ore before 
the steel making stage. Therefore, the present study was carried out on sulfur element which founded in Ghorabi iron ore, using chemical analysis composition of 169 bore holes data to trace the sulfur element distribution in Bahariya Oasis, Ghorabi mine area, Western desert, Egypt, to control the sulfur percent during the mine planning stage. $\mathrm{Gs}^{+}$ software was used to construct the variograms and kriging. According to the data arrangement, the specified parameters for constructing variograms and kriging were introduced to the program. The boreholes location and some major faults were shown in Fig. 3.

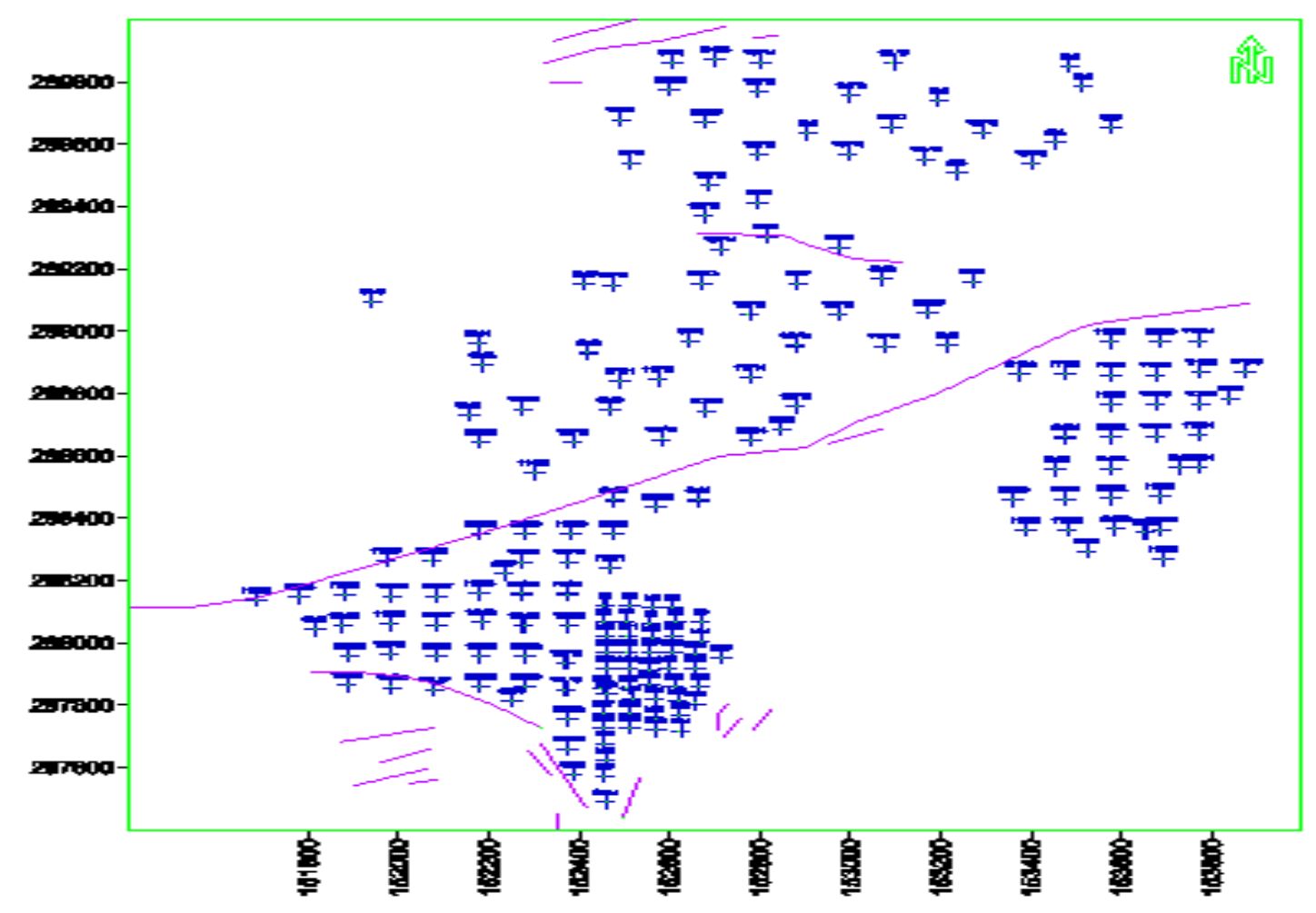

Fig. 3: boreholes location and all attributes of Ghorabi iron ore deposit, Bahariya Oasis, Western Desert, Egypt.

\section{RESULTS AND DISCUSSIONS}

\subsection{Statistical Analysis}

Traditional statistical methods assume that all sample values are equally indicative of the deposit under investigation, and the physical placements of the samples in relation to one another are ignored. in this study Statistical analysis, yielded the sulfur content distribution and standard parameters such as mean, standard deviation, coefficient of variation, variance, coefficient of skewness and coefficient of kurtosis. Table 1 show that all zones have normal distribution and as previously mentioned the allowable sulfur 
percent in the hot metal must not exceed $0.01 \%$ but as seen in Table 1 the mean values for all zones exceed that percent. The south east and north zones record a high variance and standard deviation values while the high value of coefficient of variation recorded in north zone and approximately the same in center and south west. On the other hand, the low value of coefficient of variation founded in the south west zone.

Table 1: Statistical parameters

\begin{tabular}{|c|c|c|c|c|c|}
\hline Parameters & $\begin{array}{c}(\mathrm{T}) \\
\text { Ghorabi }\end{array}$ & $\begin{array}{c}(\mathrm{N}) \\
\text { Ghorabi }\end{array}$ & $\begin{array}{c}(\mathrm{C}) \\
\text { Ghorabi }\end{array}$ & $\begin{array}{c}(\mathrm{SE}) \\
\text { Ghorabi }\end{array}$ & $\begin{array}{c}(\mathrm{SW}) \\
\text { Ghorabi }\end{array}$ \\
\hline Number of Boreholes & 169 & 24 & 29 & 30 & 86 \\
\hline Minimum & 0.19 & 0.32 & 0.21 & 0.19 & 0.27 \\
\hline Maximum & 2.01 & 2.01 & 1.4 & 1.79 & 1.51 \\
\hline Mean & 0.69 & 0.75 & 0.73 & 0.9 & 0.58 \\
\hline Standard Deviation & 0.34 & 0.43 & 0.3 & 0.43 & 0.22 \\
\hline Variance & 0.11 & 0.19 & 0.09 & 0.19 & 0.05 \\
\hline Skewness & 1.44 & 1.46 & 0.33 & 0.48 & 1.61 \\
\hline Kurtosis & 5.04 & 4.28 & 2.23 & 2.01 & 7.21 \\
\hline Coefficient of Variation & 0.49 & 0.58 & 0.41 & 0.48 & 0.38 \\
\hline
\end{tabular}

\subsection{Geostatistical Analysis}

\subsubsection{Variogram}

as illustrated in Fig. 4 isotropic variogram were produced and fitted to an appropriate model based on the available data for each location. Table 2 summarizes the variogram parameters for S percent in the analyzed areas. The variogram models for every zone as shown in Fig. 4. indicate that every zone has it's specific characterization in sulfur distribution and that obviously from the different models fitted for every zone since exponential model appears in the central zone where the gaussian model recorded in both north and south east zones and finally linear model for south west zone. As shown from geostatistical parameter in Table 2 zones (SE) and (N) recorded the lowest nugget effect and that is mean in the short range there is high continuity on the other hand it has the high sill and that is mean there is high variation between sample values. 

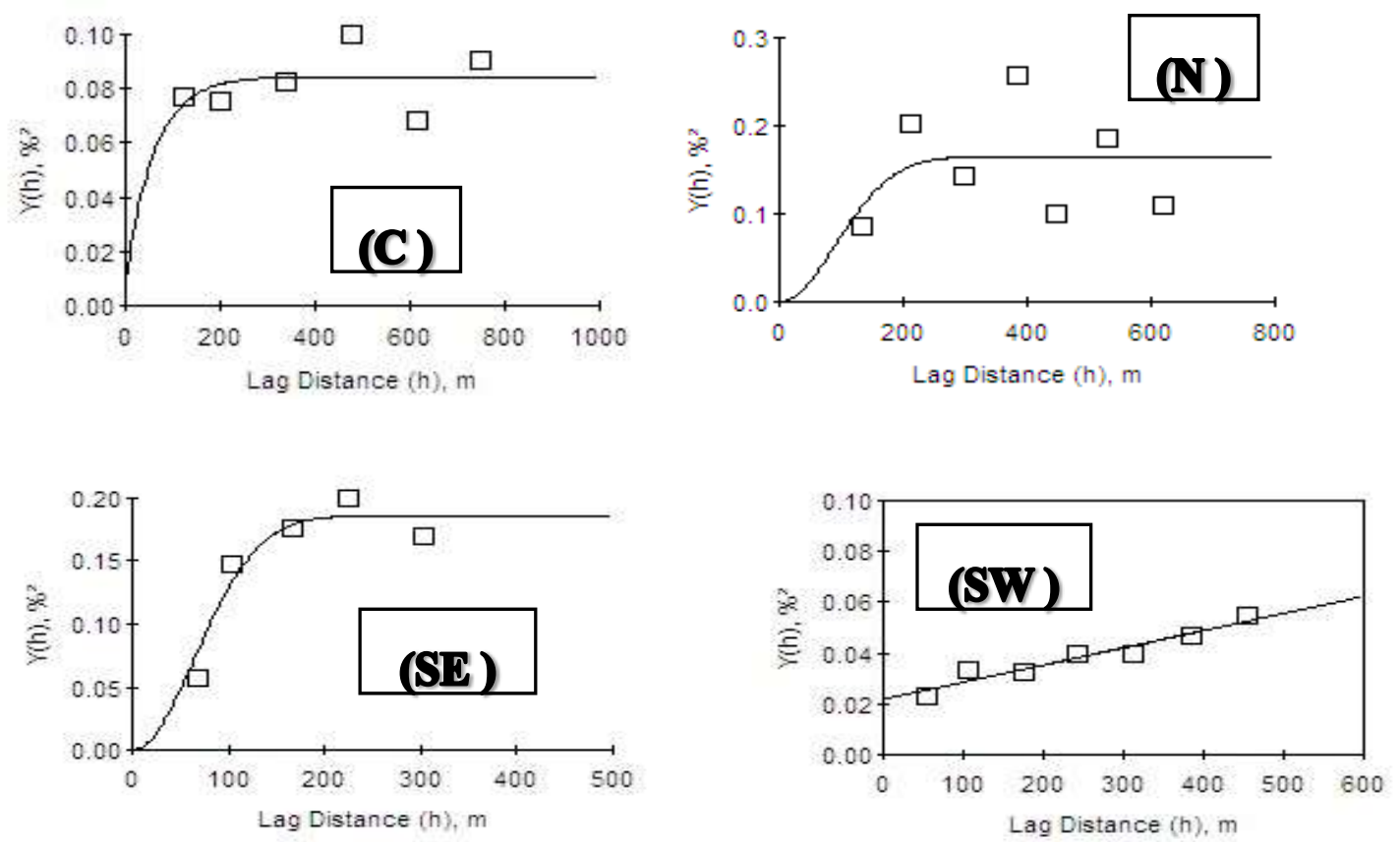

Fig. 4: Variogram models for S\% in the four studied zones

Table 2: Geostatistical parameters

\begin{tabular}{|c|c|c|c|c|}
\hline Parameters & $(\mathrm{C})$ zone & $(\mathrm{N})$ zone & $(\mathrm{SE})$ zone & $(\mathrm{SW})$ zone \\
\hline Model type & Exponential & Gaussian & Gaussian & Linear \\
\hline $\mathrm{C}_{\mathrm{o}}(\%)^{2}$ & 0.01 & 0.00 & 0.00 & 0.02 \\
\hline $\mathrm{C}_{\mathrm{o}}+\mathrm{C}(\%)^{2}$ & 0.085 & 0.16 & 0.17 & without \\
\hline Range $\mathrm{m}$ & 183 & 223 & 160 & without \\
\hline
\end{tabular}

. The central zone recorded the smallest sill and in the same time recorded a small nugget effect and that is mean in the short range as well as the long range there is a low variation between the sample values. The highest range was recorded in the north zone. The lowest range was recorded in south east zone. From all these observes can concluded that the sulfur distribution has a specific distribution for every zone separately.

\subsubsection{Ordinary Kriging}

Ordinary Kriging is used to interpolate the unknown places by constructing a map analysis that shows the distribution of $\mathrm{S}$ percent in researched areas as shown in Fig.5. It is clear that the distribution vary greatly from one zone to another. The maximum variation in distribution founded in the SE zone and the low variation recorded in SW zone while the $\mathrm{N}$ and $\mathrm{C}$ zones recorded a moderate variation. Low percent of sulfur founded in the south east zone where the value is 0.19 . The highest percent of all is 2.01 is 
founded in north zone. There are some areas have a high percent of sulfur far away from the desired percent and the optimum solution for this problem is blinding process or isolation of these areas by selective mining. As shown from Fig. 5. it is strongly suggested that the production must be from all zones at the same time to keep the percent of sulfur at the allowable percent to blast furnace. These distribution maps are very useful in mine planning, they may takes as a strong guide where selecting the production faces, blinding process and the best direction for production.
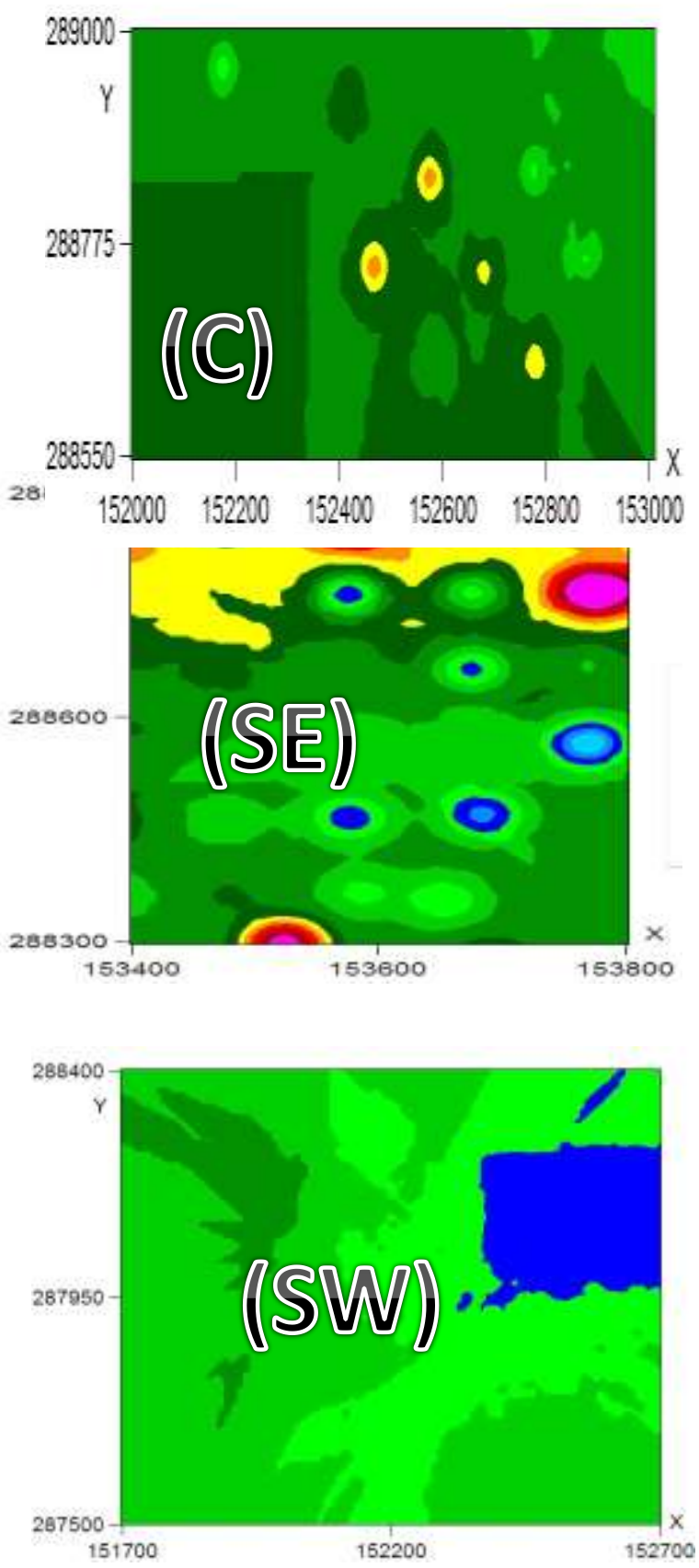

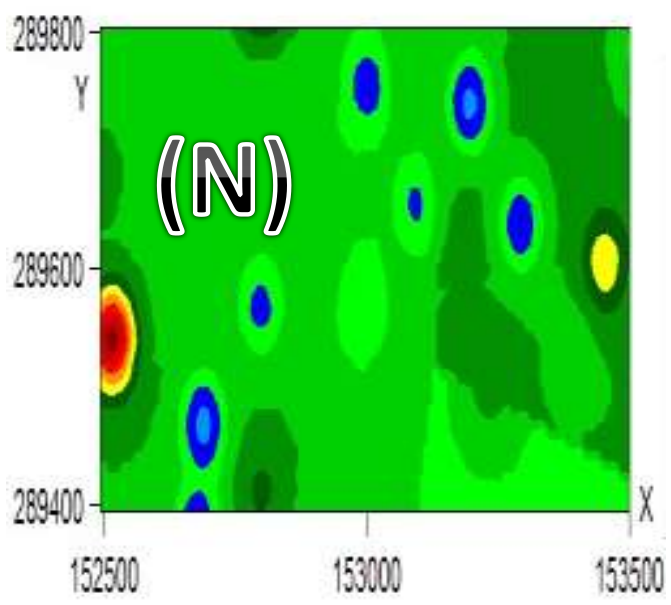

Sulfur, $\%$

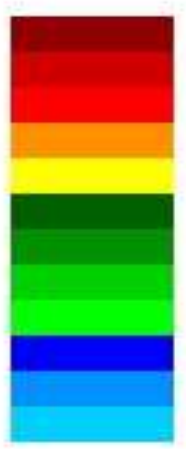

1.40

1.30

1.20

1.10

1.00

0.90

0.80

0.70

0.60

0.50

0.40

0.30

0.20

Fig. 5: Ordinary Kriged models shows Sulfur \% distribution in studied zones. 


\subsubsection{Indicator Kriging}

When employed with naturally categorical variables like facies or continuous variables that have been thresholded into categories, Indicator kriging is very beneficial for retaining the interconnectivity of high and low permeability regions. Indicator kriging models for the studied zones were constructed at cut-off grade $0.7 \%$ to show and identify the areas which above and dawn the indicated cut-off. Fig. 6. shows clearly the areas above and dawn the selected cut-off.
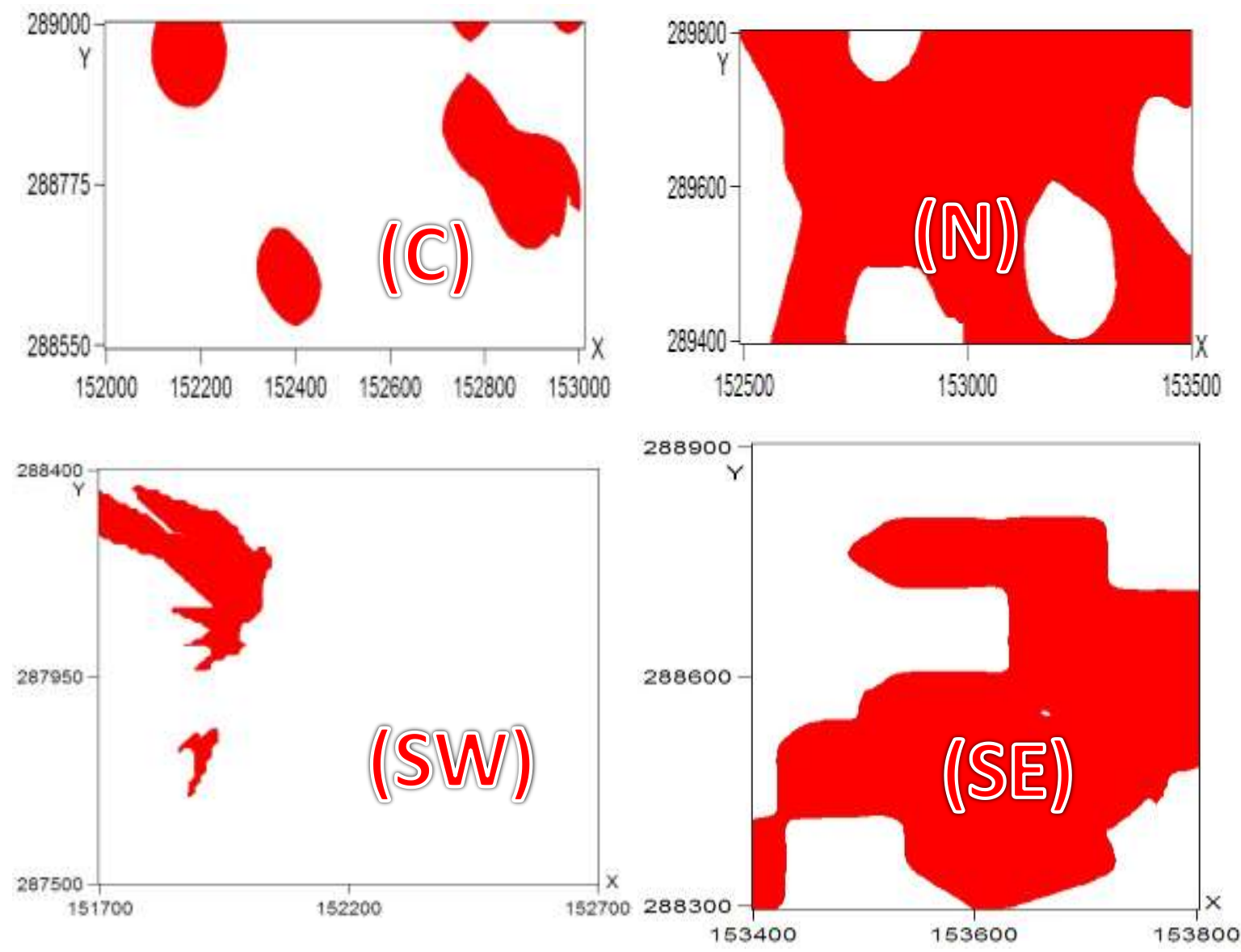

Fig. 6: indicator Kriged models shows Sulfur \% distribution at $0.7 \%$ cut-off grade in studied zones.

The white color area is the area dawn the cut-off where the colored areas indicate the area above the cut-off and consequently easy choose the faces for production. In the central and south west zones there are no problem with the Sulfur percent because the major area founded under the cut-off. 
The colored areas in the south east and north zones, on the other hand, reflected the most locations of very high Sulfur percent, as demonstrated by the colored patches in these two zones.

\section{CONCLUSIONS}

The following conclusion may be obtained from this study:

1- The behavior of sulfur mineralization inside the deposit, as reflected by the variograms, was elucidated using geostatistical techniques.

2- Geostatistical analysis allows predicting the sulfur percent for the unsampled locations along the studied area. This information can facilitate the optimization and maintenance suitable percent required for blast furnace.

3- Geostatistical analysis can be used successfully in constructing a distribution map for sulfur that strongly useful in mining planning and production.

4- Ordinary and indicator kriging models clearly indicated the high and low areas in Sulfur percent and consequently help in choosing the production faces and directions.

\section{REFERENCES}

1- Stephen, A., 1993 Avariography primer, Gibbs Associates.

2- Clark, I., 1979 Practical Geostatistics, Applied Science, Publishers Ltd, London.

3- Matheron, G., 1962 Traité de Gé ostatistique Appliqué e, Vols. 1 and 2.

4- A. F. Ismael, 2003. Effect of geologic setting on geostatistical evaluation of ore reserves. M.Sc. Thesis, Al-Azhar University. Cairo, Egypt.

5- El Aref, M. M., Mesaed, A. A., Khalil, M. A., and Salama, W. S., 2006. Stratigraphic setting, facies analyses and depositional environments of the Eocene ironstones of Gabal Ghorabi mine area, El Bahariya depression, Western Desert, Egypt. Egyptian Journal of geology, V. 50, 29-57.

6- El Aref, M.M., and Lotfy,Z.H., 1989 “ Genetic Krast Significance of the Iron Ore Deposit of Bahariya Oasis, Western Desert, Egypt”. Ann. Geo. Surv. Egypt, XV, 1-30.

7- Matheron, G., 1962 Traité de Gé ostatistique Appliqué e, Vols. 1 and 2.

8- Jared Deutsch, 2015. Experimental Variogram Tolerance Parameters, University of Alberta.

9- Michael, E. H., 1988. Geostatistics And Petroleum Geology, West Virginia Geological and Economic Survey, Van Nostrand Reinhold, New York. 
10- Darling, P., 2011. SME Mining Engineering Handbook, Third Edition, Society of Mining, Metallurgy, and Exploration.

11- Rashad, M. Z., El Qadi, G., and Ushijima, K., 2000. Selection of variogram models, Memoirs of the Faculty of Engineering, Kyushu University, v. 60, No. 3, 105-115

12- Guarascio, M., David, M., and Huijbregts, 1975. Advanced Geostatistics Proceedings the Mining Industry, University of Roma. Italy.

13- Ahmed, S., and Marsily, G., 1978. Comparison of geostatistical methods for estimating transmissivity using data on transmissivity and specific capacity, Water Resources Research, 23 (9): 1717-1737.

14- Cressie, N., 1990. The origins of kriging, Mathematical Geology Journal, 22: 239252.

15- Zimmerman, D., Pavlik, C., Ruggles, A., and Armstrong, M. P., 1999. An Experimental Comparison of Ordinary and Universal Kriging and Inverse Distance Weighting, Mathematical Geology, vol. 31, 375-390.

16- Krivoruchko, K., and Gotway, C. A., 2004. Creating Exposure Maps Using Kriging, Public Health GIS News and Information. 